\title{
An Erwinia amylovora inducible promoter for intragenic improvement of apple fire blight resistance
}

Key message: $p P P O 16$, the first Ea-inducible promoter cloned from apple, can be a useful component of intragenic strategies to create fire blight resistant apple genotypes.

Gaucher Matthieu${ }^{1}$, Righetti Laura ${ }^{2}$, Aubourg Sébastien ${ }^{1}$, Dugé de Bernonville Thomas ${ }^{3}$, Brisset Marie-Noëlle $^{1}$, Chevreau Elisabeth ${ }^{1}$, Vergne Emilie ${ }^{1}$

${ }^{1}$ IRHS, INRA, Agrocampus-Ouest, Université d'Angers, SFR 4207 QUASAV, 42 rue Georges Morel, 49071 Beaucouzé cedex, France

${ }^{2}$ present address: Protein Technologies Limited, Greenheys building, Manchester Science Park, M15 6JJ Manchester, UK

${ }^{3}$ present address: EA2106 Biomolécules et Biotechnologies Végétales, UFR Sciences Pharmaceutiques, Université François Rabelais, 31 avenue Monge, 37200 Tours, France

Matthieu Gaucher and Laura Righetti should be considered joint first authors

Correspondence: Emilie Vergne

Emilie.vergne@inra.fr

Keywords: Intragenesis, Polyphenoloxidases, Apple, Fire blight, Scab

\begin{abstract}
Intragenesis is an important alternative to transgenesis to produce modified plants containing native DNA only. A key point to develop such a strategy is the availability of regulatory sequences controlling the expression of the gene of interest. With the aim of finding apple gene promoters either inducible by the fire blight pathogen Erwinia amylovora $(E a)$ or moderately constitutive, we focused on polyphenoloxidase genes $(P P O)$. These genes encode oxidative enzymes involved in many physiological processes and have been previously shown to be up-regulated during the $E a$ infection process. We found ten PPO and two PPO-like sequences in the apple genome and characterized the promoters of MdPPO16 ( $p P P O 16$ ) and MdKFDVO2 PPO-like ( $p K F D V 02$ ) for their potential as Ea-inducible and lowconstitutive regulatory sequences respectively. Expression levels of reporter genes fused to these promoters and transiently or stably expressed in apple were quantified after various treatments. Unlike $p K F D V 02$ which displayed a variable activity, $p P P O 16$ allowed a fast and strong expression of transgenes in apple following $E a$ infection in a Type 3 Secretion System dependent manner. Altogether our results indicate that $p K F D V 02$ did not keep its promises as a constitutive and weak promoter whereas $P P P O 16$, the first $E a$-inducible promoter cloned from apple, can be a useful component of intragenic strategies to create fire blight resistant apple genotypes.
\end{abstract}




\section{Introduction}

Intragenesis and cisgenesis are alternatives to transgenesis defined by Rommens et al. (2007) and Schouten et al. (2006) respectively, and are based on the exclusive use of genetic sequences from the same (or a sexually compatible) species. These strategies aim at improving crop breeding while taking into account the public's reluctance toward the use of foreign genes usually present in the genetically modified plant varieties. In the case of cisgenesis, coding sequences (CDS) must be in a sense orientation and flanked by their native promoter and terminator sequences, while intragenesis allows a reorganization of both regulatory and coding sequences, as well as the introduction of mutations (e.g., nucleotide substitutions, sequence deletions, duplications and inversions), to fine tune the expression of the CDS of interest (Holme et al. 2013). These techniques are of particular interest for perennial vegetatively propagated crops such as apple (Malus $x$ domestica Borkh.) for which conventional breeding is very time-consuming (Limera et al. 2017). In addition, the selectable marker gene is eliminated from cisgenic as well as from intragenic plants, thus allowing sequential introduction of a new transgene, using the same selectable marker, in an elite variety (Halpin 2005).

Erwinia amylovora $(E a)$ is a necrogenic enterobacterium causing progressive necrosis on flowers and succulent shoots in members of the Malinae tribe of the Rosaceae family including apple (Vanneste 2000). Rapid invasion of the bacteria into branches and trunks can lead to the death of the trees within a growing season for the most susceptible cultivars. At the cellular level, the bacteria use a Type 3 Secretion System (T3SS) to deliver effectors into the plant cells, to induce membrane disruption and oxidative burst leading to cell death (Vrancken et al. 2013). $\mathrm{H}_{2} \mathrm{O}_{2}$ is one of the first detectable ROS (Reactive Oxygen Species) produced during this infection process (Vrancken et al. 2013). Fire blight outbreaks are sporadic, particularly difficult to control and improving host resistance is by far the most effective option to control the disease (Paulin, 1996). Breeding for Fire blight resistance is therefore an active area of research with the identification of genetic resistance factors including quantitative traits loci (Khan et al. 2012), a "resistance" gene (R gene) implicated in pathogen recognition (Vogt et al., 2013) or defense mechanisms downstream recognition (Vrancken et al. 2013).

Numerous attempts to create fire blight resistant apple transgenic lines have been performed with various degrees of success. For example, a number of studies were based on the expression of foreign genes encoding insect lytic proteins (Borejsza-Wysocka et al. 2010), a viral EPS-depolymerase (Flachowsky et al. 2008a) or the $E a \mathrm{HrpN}$ protein (Vergne et al. 2014). Other studies tested the effect of overexpressing apple genes such as MpNPRI (Malnoy et al. 2007), MbR4 R gene (Flachowsky et al. 2008b) or silencing apple genes such as HIPM (Malnoy et al. 2008) or FHT (Flachowsky et al. 2012). However, to our knowledge, intragenic strategies have never been employed to improve apple resistance to $E a$.

The generation of intragenic/cisgenic apple plants requires the development and combination of different strategies. The selection of transgenic lines can be based on alternative selectable marker genes from apple such as genes implicated in anthocyanin production (Kortstee et al. 2011) or genes of which certain mutation gives resistance to herbicide (acetolactate synthase ; Yao et al. 2013). A recombinase-mediated removal of the unwanted selectable marker sequence has also been used (Herzog et al. 2012; Righetti et al. 2014; Kost et al. 2015).

As for the regulatory sequences, so far, only the apple Rubisco promoter has been used to obtain a constitutive and high expression of the intragene Rvi6 to control apple scab, an apple disease caused by the fungi Venturia inaequalis (Vi, Joshi et al. 2011). However, to fully exploit intragenesis, diverse apple regulatory sequences are strongly needed. Fine-tuning intragene expression in the plant may be useful to save energy and eventually to increase the 
efficacy of the intragene itself. In order to create apple intragenic lines resistant to $E a$, we were interested in two kinds of regulatory sequences: (i) an inducible promoter with a fast and strong induction after $E a$ infection and able to trigger the production of defense mechanisms in the right place at the right time against the bacteria and (ii) a constitutive promoter with a moderate expression level. Such a promoter could ensure the permanent presence of immune receptors such as pattern recognition ones or ones encoded by $\mathrm{R}$ genes, with minimal negative tradeoff effects. With a strong constitutive promoter, the risk would be to excessively divert plant energy toward metabolisms other than growing and developing. Previous results led us to investigate the family of polyphenol oxidases (PPO) for this purpose. This complex family of enzymes catalyzes the hydroxylation of monophenols and/or the oxidation of di-phenolic compounds into quinones (Pourcel et al. 2007). A high increase of global enzyme activity has been reported in apple after Ea infection (Skłodowska et al. 2011; Gaucher et al. 2013) and preliminary studies on gene expression by RT-qPCR revealed a clear differential induction of $P P O$ genes - or set of genes - after infection (Dugé de Bernonville, 2009).

Here, we took advantage of the recent high-quality apple genome (Daccord et al. 2017) to fully describe the apple PPO family and to select individual genes with differential expression after $E a$ infection. After cloning, promoters of interest were fused to reporter genes and transiently or stably transformed in apple. This allowed the evaluation of their activity under various stresses in order to evaluate their usefulness in future intragenesis strategies for apple resistance to $E a$.

\section{Material and Methods}

\section{Material, growth and inoculation conditions}

\section{Apple}

Four Malus $x$ domestica genotypes were used in this work: the ornamental cv. 'Evereste', the rootstock 'MM106' and the table apples 'Golden Delicious' and 'Gala'. Experiments were performed in greenhouse on actively growing shoots of young grafts ('Evereste' and 'MM106') grafted on 'MM106', or on actively growing plants not grafted ('Golden Delicious'), and grown under greenhouse conditions (natural photoperiod, temperatures between 17 and $22^{\circ} \mathrm{C}$ ). Experiments were also performed on in vitro-growing shoots of three to four $\mathrm{cm}$, used 4 weeks after rooting (Online Resource 1). Micropropagation conditions were as described in Righetti et al. (2014) and rooting conditions as previously reported (Faize et al. 2003).

\section{Erwinia amylovora culture, inoculation and experiments}

Two Ea strains were used in this study: wild-type $E a$ CFBP1430 (Ea wt; Paulin and Samson, 1973) and PMV6023, a non-pathogenic T3SS-defective mutant of $E a$ wt, mutated in $h r c \mathrm{~V}$ (Ea t3ss; Barny, 1995). Prior to each experiment, bacteria were subcultured at $26^{\circ} \mathrm{C}$ overnight on solid King's medium B (King et al. 1954) supplemented with chloramphenicol $(20 \mu \mathrm{g} / \mathrm{mL})$ for the mutant. Bacterial inocula were prepared in sterile distilled water to yield a concentration of $10^{7}$ colony-forming units $(\mathrm{CFU}) / \mathrm{mL}$, supplemented with $0.01 \%(\mathrm{v} / \mathrm{v})$ of wetting agent Silwet (L-77, De Sangosse Ltd, Cambridge, UK). Mock corresponded to sterile water supplemented with the wetting agent Silwet.

For greenhouse growing plants inoculation was performed by vacuum infiltration as described in Pontais et al. (2008). Briefly, the top of growing shoots were submerged in bacterial suspension and the vacuum was applied for $2 \mathrm{~min}$ at $-0.09 \mathrm{Mp}$ (Online Resource 1). 
In related experiments, leaf samples were immediately frozen in liquid nitrogen and kept at $-80^{\circ} \mathrm{C}$ until analysis. Sampling concerned the youngest expanded leaf of each plant labeled the day of the inoculation. Each sample is a pool of leaves from three different plants and two ( $\mathrm{n}=2$; PPO genes expression analysis in 'Evereste' and 'MM106' genotypes) to three ( $\mathrm{n}=3$; promoters analysis in 'Golden Delicious' transgenic lines) biological repeats have been made by condition (genotype/transgenic line $\mathrm{x}$ treatment $\mathrm{x}$ time).

For in vitro-growing shoots, four weeks after rooting, shoots were separated from their roots, totally submerged in inoculum and vacuum infiltrated for 2 min at $-0.09 \mathrm{Mp}$. Shoots were then dried on sterile filter paper and placed for 1 day back on micropropagation medium before sampling.

In related experiments, leaf samples were immediately frozen in liquid nitrogen and kept at $-80^{\circ} \mathrm{C}$ until analysis. Sampling concerned all the leaves of each shoot. Each sample is a pool of leaves from three different plants and three $(n=3$; transient transformation assay on 'Gala' genotype) to six ( $\mathrm{n}=6$; in vitro experiments on 'Golden Delicious' transgenic lines) biological repeats have been made by condition (genotype/transgenic line x treatment $\mathrm{x}$ time).

\section{Venturia inaequalis culture, inoculation and experiment}

The apple scab monoconidial isolate used was EU-B04 from the European collection of $V$. inaequalis from the European project Durable Apple Resistance in Europe (Lespinasse et al. 2000). Inoculum was prepared as described by Parisi and Lespinasse (1996) to obtain a final concentration of $2.5 \times 10^{5}$ conidia/mL. Inoculation was performed as described by Parisi et al. (1993). Briefly, conidial suspension was applied to runoff on leaves with a manual sprayer. Plants were then incubated for two days under plastic tarpaulin and sprayed three times a day to assure constant leaf wetness. The tarpaulin was then removed and plants grew under greenhouse conditions. Mock corresponded to sterile water.

Leaf samples were immediately frozen in liquid nitrogen and kept at $-80^{\circ} \mathrm{C}$ until analysis. Sampling concerned the youngest expanded leaf of each plant labeled the day of the inoculation. Each sample is a pool of leaves from three different plants and three biological repeats $(n=3)$ have been made by condition (transgenic line $x$ treatment $x$ time).

\section{Agrobacterium culture}

Agrobacterium tumefaciens EHA105 (Hood et al. 1993) containing binary expression vectors of interest (Online Resource 2) was cultured on LBA (LB Agar, Sigma-Aldrich, St. Louis, MO, USA) supplemented with appropriate antibiotics and incubated at $28^{\circ} \mathrm{C}$ for two days.

\section{$\mathrm{H}_{2} \mathrm{O}_{2}$ treatment}

$\mathrm{H}_{2} \mathrm{O}_{2}(30 \%$ w/v solution, Fisher Scientific, Loughborough, UK) was used at $10 \mathrm{mM}$ concentration on in vitro-growing shoots. Four weeks after rooting, shoots were separated from their roots and either cultured on micropropagation medium supplemented with $10 \mathrm{mM}$ $\mathrm{H}_{2} \mathrm{O}_{2}$ during 1 day before sampling or vacuum infiltrated for $2 \mathrm{~min}$ at $-0.09 \mathrm{Mp}$, dried on sterile filter paper and placed for 1 day back on micropropagation medium before sampling.

Leaf samples were immediately frozen in liquid nitrogen and kept at $-80^{\circ} \mathrm{C}$ until analysis. Sampling concerned all the leaves of each shoot. Each sample is a pool of leaves from three different plants and six ( $\mathrm{n}=6$; in vitro experiments on 'Golden Delicious' transgenic lines) biological repeats have been made by condition (transgenic line $\mathrm{x}$ treatment $\mathrm{x}$ time). 


\section{Transformation of apple}

Agroinfiltration of in vitro rooted plants was used for transient transformation experiments. The inoculum for infiltration was a mix of the strain with the T-DNA of interest (Online Resource 2: $p 35 S$, $p K F D V 02$ or $p P P O 16$ from MM106) and the strain with the TDNA carrying the gene coding the 19 protein of tomato bushy stunt virus as a suppresser of gene silencing (Voinnet et al. 2003), respectively at $5 \times 10^{8} \mathrm{CFU} / \mathrm{mL}$ and $2.5 \times 10^{8} \mathrm{CFU} / \mathrm{mL}$. The cultures were re-suspended in induction buffer (10 mM MES pH 5.6, $10 \mathrm{mM} \mathrm{MgCl} 2,2 \%$ (w/v) sucrose and $150 \mu \mathrm{M}$ acetosyringone) (Santos-Rosa et al. 2008), mixed at the desired concentration, incubated at $28^{\circ} \mathrm{C}$ with shaking for $3 \mathrm{~h}$, and then supplemented with $0.002 \%$ (v/v) of wetting agent Silwet before use. Four weeks after rooting, shoots were separated from their roots, totally submerged in inoculum and vacuum infiltrated for 2 min at $-0.09 \mathrm{Mp}$. Shoots were then rinsed in 3 successive baths of sterile water, dried on sterile filter paper and placed for 6 days back on micropropagation medium without antibiotics before sampling.

Stable transformation experiments were carried out according as previously reported (Righetti et al. 2014). Presence of transgenes and absence of contaminating agrobacteria were monitored by PCR and sequencing of PCR products. Genomic DNA of apple leaves was extracted as described in Fulton et al. (1995). Primers used for the detection of (i) $A$. tumefaciens presence, (ii) nptII gene, (iii) p35S:GUS straddled amplification (iv) pPPO16:GUS straddled amplification, (v) pKFDV02:GUS straddled amplification and (vi) elongation factor $1 \alpha(E F-1 \alpha)$ coding gene as a marker of plant DNA suitability for PCR are available in Online Resource 3. Amplifications were performed using GoTaq ${ }^{\circledR}$ Flexi DNA Polymerase (Promega, Madison, WI, USA) according to the manufacturer's recommendations. The PCR reaction conditions were identical for the six genes except the hybridization step which was at $55^{\circ} \mathrm{C}$ and not $58^{\circ} \mathrm{C}$ for $A$. tumefaciens detection primers: $95^{\circ} \mathrm{C}$ for $5 \mathrm{~min}$, followed by 35 cycles at $95^{\circ} \mathrm{C}$ for $30 \mathrm{~s}, 58^{\circ} \mathrm{C}$ for $45 \mathrm{~s}, 72^{\circ} \mathrm{C}$ for $1 \mathrm{~min}$ and 30 $\mathrm{s}$, with a final extension at $72^{\circ} \mathrm{C}$ for $5 \mathrm{~min}$. The PCR products were separated on a $2 \%$ agarose gel. Transgenic lines and control plants were then propagated in vitro and acclimatized in a greenhouse as previously reported (Faize et al. 2003). Before acclimatization, the ploidy level of transgenic lines was checked by flow cytometry, as described in Chevreau et al. (2011), and tetraploid lines were eliminated.

\section{Characterization of apple PPO family}

The annotated genes of the 'Golden Delicious' double haploid 13 genome (Daccord et al. 2017) have been screened for PFAM motifs specific to the PPO family, namely PF12142 and PF12143. The structural annotation of each detected locus was manually evaluated in considering BLASTX results and RNA contig alignments. The integrity of CDS has cautiously been checked in order to differentiate functional genes from pseudogenes. The twelve protein sequences deduced from complete and short CDS have been analyzed with targetP (Emanuelsson et al. 2007) and Predotar (Small et al. 2004) for the prediction of Nterminal targeting peptide for the plasts. Phylogenetic tree was built from full-length alignment with Neighbor-joining method, excluding gap positions and tested with Bootstrap method (Kumar et al. 2016). The percent identity matrix of CDS and proteins were built with MUSCLE (Edgar, 2004) and Clustal Omega (Sievers et al. 2011) respectively.

\section{Cloning of promoters}


Sequence of CaMV 35S promoter in pK7WG2D (Karimi et al. 2002) and sequences of about $2 \mathrm{~kb}$ upstream MdPPO16 (MD10G1299400) and MdKFDV02 CDS (MD10G1298200) were downloaded. Primers for cloning (Online Resource 3) were designed with primer3plus (http://www.bioinformatics.nl/cgi-bin/primer3plus/primer3plus.cgi). Genomic DNA of apple 'MM106' was used as template for PCR amplification of promoters with a high fidelity DNA polymerase (Phusion Hot Start II DNA Polymerase, ThermoFisher Scientific, MA, USA) used according to the manufacturer instructions. Amplified fragments were then cloned into pGEM-T easy (Promega, Madison,WI, USA) or p-ENTR/D TOPO (Invitrogen, Carlsbad, CA, USA) when subsequent Gateway cloning was planned.

For apple stable transformation, promoters were cloned with the Gateway system via pENTR-D TOPO (Invitrogen, Carlsbad, CA, USA) into the destination vector pKGWFS7 (Karimi et al. 2002). In this vector the sequence under study controls the expression of a GUS-GFP reporter gene. 2219 bp upstream to MdPPO16 and 2030 bp upstream to MdKFDV02 start codons were cloned and the final constructs were transformed in Agrobacterium strain EHA105 with the helper plasmid pBBR-MCS5. As a positive control for stable transformation assays a plasmid pKGWFS7 carrying the CaMV 35S promoter was used (Online Resource 2).

For transient assays we used either the same plasmids as for stable transformation, or the binary vector pGREEN II 0800-LUC (Hellens et al. 2005). This vector is specifically designed to clone the sequence under study upstream to a firefly luciferase coding sequence. A Renilla luciferase coding sequence under the control of a constitutive CaMV 35S promoter is also present as an internal control. The presence of the two luciferases in a single T-DNA reduces the intrinsic variability of leaf agroinfiltration and thus allows reproducible promoter activity quantification. Cloning into this vector was achieved by adding specific restriction sites to the primers. KpnI and NcoI sites were added to the 5' and 3' ends respectively of MdPPO16 and MdKFDV02 promoters, while KpnI and HindIII were added to primers used for CaMV $35 \mathrm{~S}$ promoter. After digestion with restriction enzymes of both vectors and inserts, $1177 \mathrm{bp}$ and $2030 \mathrm{bp}$ of the sequences upstream the start codon were cloned for MdPPO16 and MdKFDV02, respectively. As a positive control for transient assays $1027 \mathrm{bp}$ of CaMV $35 \mathrm{~S}$ promoter amplified from the plasmid pK7WG2D (Karimi et al. 2002) were also cloned. The final constructs were transformed in Agrobacterium strain EHA105 with the helper plasmid pSoup (Online Resource 2).

\section{DNA extraction, RNA extraction, reverse transcription, and gene expression analysis} (1995).

Genomic DNA of leaves of apple 'MM106' was extracted as described in Fulton et al.

For RNA extraction, frozen leaves were ground to a fine powder in a ball mill (MM301, Retsch, Hann, Germany). RNA from leaves was extracted as described in Venisse et al. (2002). Purity and concentration of the samples were assayed with a Nanodrop spectrophotometer (ThermoScientific, Rockford, IL, USA). Reverse transcription was performed with M-MLV as described by Promega with OligodT $25 \mathrm{ng} / \mu \mathrm{l}$ or specific primers $0.04 \mu \mathrm{M}$ final concentrations (Online Resource 3). Intron-spanning primers designed on the $E F-1 \alpha$ gene were used to check the absence of genomic DNA contamination.

Quantitative PCR was used to quantify cDNA in samples. Briefly, $3.75 \mu \mathrm{L}$ of the appropriately diluted samples (ranging from 4 to 12.5 -fold) were mixed with $7.5 \mu \mathrm{L}$ of qPCR mastermix (MasterMix Plus for $\mathrm{SYBR}^{\odot}$ Green I with fluorescein, Eurogentec, Liège, Belgium) in a final volume of $15 \mu \mathrm{L}$. Primers designed with Primer3Plus were added according to their optimal concentration (determined for reaction efficiency near to $100 \%$; 
calculated as the slope of a standard dilution curve; Pfaffl, 2001). Primer sequences are indicated in Online Resource 3. Reaction was performed on a DNA Engine thermal cycler Chromo4 (Bio-Rad, Hercules, CA, USA) using the following program: $95^{\circ} \mathrm{C}, 5 \mathrm{~min} ; 35$ cycles comprising $95^{\circ} \mathrm{C} 15 \mathrm{~s}, 60^{\circ} \mathrm{C} 45 \mathrm{~s}$ and $72^{\circ} \mathrm{C} 30 \mathrm{~s}$ with real-time fluorescence monitoring. Melt curves were performed at the end of each run to check the absence of primer-dimers and non-specific amplification products. Data were acquired and analyzed with MJ Opticon Monitor Software 3.1 (Bio-Rad, Hercules, CA, USA). Expression profiles of endogenous $P P O$ genes were calculated using the $2^{-\Delta \Delta \mathrm{Ct}}$ method and were corrected as recommended in Vandesompele et al. (2002), with three internal reference genes (GADPH, $T u A$ and Actin) used for the calculation of a normalization factor. Data were transformed into $\log _{2}$ scale. Expression levels of the GUS and FIRE reporter genes were calculated using the $2^{-}$ ${ }^{\triangle \mathrm{Ct}}$ method and were corrected with the spectinomycin $(S P E C)$ selection gene or the internal control REN respectively. GUS in pKGWFS7 did not possess an intron so in the transient assay this reporter gene actually dosed expression from both the plant and Agrobacterium. $S P E C$ gene expression, specific from the bacteria because present in the plasmid but not in the T-DNA, was used to calibrate samples amongst themselves to eliminate the potential part of expression due to bacteria in the GUS measure differences.

\section{Luciferase activity assay}

Frozen leaves were ground to a fine powder in a ball mill (MM301, Retsch, Hann, Germany). Luciferase activities were measured by using the dual luciferase assay system (Promega, Madison, USA) according to the manufacturer's instructions but with some modifications. $150 \mu \mathrm{L}$ of Passive Lysis Buffer were added to the resulting powders and samples were placed on ice for $15 \mathrm{~min}$ and vortexed several times in the meantime. For luciferase activity measurements (firefly and renilla), $10 \mu \mathrm{L}$ of each extract were transferred into a 96-well white solid plate (Fisher Scientific ltd., Montreal, Quebec). The luminescence was measured using the FluoStar Optima Luminometer (BMG Lab Technologies, Offenburg, Germany) with the injection of $60 \mu \mathrm{L}$ of LARII reagent (Firefly luciferase activity) and then $60 \mu \mathrm{L}$ of the Stop \& Glo reagent (Renilla luciferase activity). Luciferase activities were standardized to the protein concentration (Bradford, 1976) of the extract and Firefly luciferase activity was normalized to Renilla luciferase activity.

\section{Statistics analysis}

All statistical analyses were performed with R 3.4 (R Development Core Team, 2016) by using the nonparametric rank-based statistical test Kruskal-Wallis. Treatments with significant influence $(\mathrm{p}<0.05)$ were studied more in depth by Fisher's Least Significant Difference (LSD) as a post hoc test for pairwise comparisons $(\alpha=0.05)$. Means with different letters are statistically significant.

\section{Data availability}

pKFDV02 (MK873006) and pPPO16 (MK873007) sequences are available in GenBank repository. Accession numbers of other sequences analyzed in this work (from repository GenBank or https://iris.angers.inra.fr/gddh13, "curated CDS" layer) are in Table 1, Online Resource 2 and 3, or in references given in these tables. Data generated during and/or analysed during the current study are available from the corresponding author on reasonable request.

\section{Results}




\section{PPO encoding genes in the apple genome}

Screening the 'Golden Delicious' double haploid 13 genome (Daccord et al. 2017) revealed the presence of a $P P O$ gene family encompassing ten members with similar gene structure of one or two exons, encoding proteins ranging from 587 to 610 residues (Table 1). $\mathrm{N}$-terminal signal peptides for chloroplast targeting were predicted for all of them. PPO proteins are characterized by three conserved PFAM domains: the tyrosinase superfamily domain PF00264, the PPOI_DWL domain PF12142 and the PPO1_KFDV domain PF12143. Apple $P P O$ genes are located on two clusters on chromosomes 5 (five genes) and 10 (five genes), two chromosomes known to result from a whole genome duplication (Daccord et al. 2017). Close examination of these two chromosomal regions identified two additional PPOlike encoding genes, one on chromosome 5 and the other on chromosome 10, which conserved only the C-terminal KFDV domain and were also predicted to be addressed to the chloroplast (Table 1). Six pseudogenes were finally found, four on chromosome 5 and two on chromosome 10. Their CDS are disrupted by deletion, transposable element insertion, frameshift and/or stop codons (Table 1). We named $P P O$ genes and pseudogenes MdPPOO1 to MdPPO16, and PPO-like genes MdKFDVO1 and MdKFDV02. Phylogeny based on 30 identified PPO Rosaceae homologs revealed five subfamilies (Fig. 1). Identity matrices obtained using nucleic or protein sequences of the ten apple PPOs showed a very high conservation level between accessions inside each apple PPO sub-family (Online Resource 4).

\section{Apple PPO gene expression profiles}

To identify $P P O$ promoters differentially responding to $E a$ infection, we quantified by RT-qPCR the specific expression of $P P O$ genes in apple infected tissues. For this study pseudogenes (MdPPO1, MdPPO4, MdPPO7, MdPPO9, MdPPO11 and MdPPO14) were discarded, as well as $M d P P O 12, M d P P O 13$ and $M d P P O 15$ for which the design of specific primers was impossible due to their high level of identity ( $\geq 97.7 \%$; Online Resource 4$)$. Primers for the remaining seven $P P O$ and the two $P P O$-like genes were designed with the aim of quantifying their expression in infected leaves of two apple genotypes with contrasted susceptibilities to fire blight, the susceptible 'MM106' and the resistant 'Evereste' (Venisse et al., 2002). During the test of primers efficacy performed using as template a cDNA pool from these apple genotypes, we obtained very weak amplifications for MdPPO02, MdPPO03, MdPPO05, MdPPO06, MdPPO08 and MdPPO10 contrasting with the substantial ones for MdKFDV01, MdKFDVO2 and MdPPO16 (Online Resource 5). Therefore gene expression kinetics are only shown for MdKFDV01, MdKFDVO2 and MdPPO16 (Fig. 2). Analyses were performed in untreated leaves and in leaves challenged either with a wild-type strain of $E a$ ( $E a$ wt) or a T3SS deficient mutant $(E a \mathrm{t} 3 \mathrm{ss})$ or mock at 6,24 and 48 hours post-treatment (hpt). A higher constitutive expression in untreated leaves of MdPPO16 and MdKFDVO2 compared to MdKFDV01 was observed in 'Evereste'. Ea t3ss and mock treatments triggered similar expression changes in the two genotypes, peaking at $6 \mathrm{hpt}$ especially for MdPPO16 probably due to the stress caused by the infiltration method. A strong increase in MdPPO16 expression was recorded in both genotypes challenged with $E a \mathrm{wt}$, suggesting a type III effector dependent induction. No noticeable modulation was observed in MdKFDVO1 and $M d K F D V 02$ expression levels whatever the treatment, except for $E a$ wt that seemed to slightly modulate the expression of MdKFDV01 in 'MM106' at 24 and $48 \mathrm{hpt}$ in one replicate only. Promoter of MdKFDV02 from 'MM106', thereafter named $p K F D V 02$, was selected for further investigation instead of promoter of MdKFDVO2 from 'Evereste' because expression 
of MdKFDVO2 was more stable throughout the kinetics (Fig. 2). Promoter of MdPPO16 from 'MM106', thereafter named $P P P O 16$, was also selected for further investigation instead of promoter of MdPPO16 from 'Evereste' because MdPPO16 expression throughout the kinetics was similar for the two genotypes (Fig. 2). We found $95.17 \%$ identity between sequences of 2218 bp length upstream MdPPO16 CDS in 'MM106' and 'Evereste'.

\section{Promoter activity during transient expression}

The regions upstream of MdPPO16 (1177 bp) and MdKFDV02 (2030 bp) CDS in 'MM106' genotype were cloned, and tested as a first approach in a transient expression assay in apple leaves using GUS ( $\beta$-glucuronidase) as a reporter to quantify promoter activity in untreated, mock or $E a$-infiltrated tissues. Rooted in vitro plants of 'Gala' were agroinfiltrated with EHA105 carrying different T-DNAs including pPPO16:GUS, pKFDV02:GUS or p35S:GUS as a control. Five days later, plants were infiltrated with mock or $E a$ wt and gene expression of GUS measured 24 hours later by RT-qPCR and calibrated to eliminate expression differences due to bacteria. GUS gene expression was stable in all samples under the control of $p K F D V 02$ (Fig. 3) and had comparable levels to that observed in Ea-infiltrated leaves under the control of $P$ PPO16. Under the control of $p P P O 16$, a strong induction of the $G U S$ expression was observed in leaves challenged with $E a$ wt (a 5-fold increase approximately, Fig. 3). The same transient expression assay was repeated once in the other genotype 'Golden Delicious' with firefly luciferase (FIRE) instead of GUS as a reporter gene (Online Resource 6), to quantify promoter activity both at the transcriptional and enzymatic level. FIRE gene expression and protein activity were stable in all samples under the control of pKFDV02 (Online Resource 6 a and $6 \mathrm{~b}$ respectively) and had comparable levels to that observed in untreated and mock-infiltrated leaves under the control of $p P P O 16$ or $p 35 S$. Under the control of $P P P O 16$, a strong induction of the FIRE activity was observed in leaves challenged with $E a$ wt, both at the transcriptional and enzymatic level (a 2-fold increase approximately, Online Resource 6 a and 6 b).

\section{Promoter activity in stable transgenic clones}

The contrasting results obtained with the transient assay encouraged us to perform apple stable transformations with two constructs carrying each promoter fused with the GUS gene as marker gene ( $p P P O 16: G U S$ and $p K F D V 02: G U S$ ), and to compare these to $p 35 S: G U S$ transformed control. We respectively obtained one, two and four transgenic lines of 'Golden Delicious' transformed with pPPO16:GUS, pKFDV02:GUS and p35S:GUS. For pPPO16:GUS, the unique line obtained was kept for subsequent analyses. For pKFDV02:GUS, the more vigorous line in vitro was kept for subsequent analyses. For p35S:GUS, subsequent analyses were performed on two lines harboring a medium GUS expression (lines $217 \mathrm{O}$ and S; Online Resource 7). Assessment of transgenic lines chose for the further analyses are displayed in Online Resource 8. After in vitro multiplication, all stable transgenic lines were acclimatized and grown in greenhouse. The expression of the reporter gene was assessed by RT-qPCR in untreated, mock and $E a$ wt-infiltrated leaves at 24 hpt. In $p K F D V 02$ lines, activity was not significantly different from $p 35 S$ lines in all conditions (nt, mock and $E a$ wt treatments, Fig. 4). By contrast, GUS expression was very weak in untreated and mock-infiltrated leaves of pPPO16:GUS lines and exhibited a strong and significant 10-fold induction in inoculated ones, reaching levels similar to p35S:GUS lines. Altogether these results corroborate the results of the transient expression assay and show that $P$ PPO16 but not $p K F D V 02$ is strongly induced by Ea infection. 
To determine which component of the $E a$ pathogenesis is responsible for the induction of $p P P O 16$, i.e. a functional T3SS of the bacterium and/or the ROS production during the infectious process, GUS expression was recorded in transgenic rooted in vitro plants carrying pPPO16:GUS and pKFDV02:GUS at $24 \mathrm{hpt}$ after the following different treatments: mock, $E a$ t3ss and $E a$ wt by leaf infiltration and $\mathrm{H}_{2} \mathrm{O}_{2}$ by leaf infiltration or by incorporation in the culture medium (Fig. 5). GUS expression was relatively stable when mediated by the promoter $p K F D V 02$, although a slight but significant decrease of activity was observed after $\mathrm{H}_{2} \mathrm{O}_{2}$ treatments (infiltration and culture medium) compared to mock treatment. No change in GUS expression was observed in pPPO16:GUS lines treated with mock, Ea t3ss and $\mathrm{H}_{2} \mathrm{O}_{2}$, while again a strong and significant 10-fold induction was observed when these lines were inoculated with $E a$ wt. Taken together, these results highlight the ability of $E a$ to strongly and specifically induce $p P P O 16$ (and not $p K F D V 02$ ), probably as an effect of a functional T3SS rather than $\mathrm{H}_{2} \mathrm{O}_{2}$ production.

In order to check $p P P O 16$ ability to be specifically activated by $E a$ and to observe pKFDV02 behavior in response to another pathogen, the same transgenic lines were challenged with the pathogenic fungus $V i$ responsible for apple scab. Transgenic lines were therefore cultivated in greenhouse and GUS expression was assessed in untreated, mock and $V i$-sprayed leaves at 1, 3 and 10 days post-treatment (dpt), the development of fungus being slower than that of Ea. Results indicated that up to $3 \mathrm{dpt}$, the $G U S$ expression mediated by pPPO16 was not affected by $V i$ in comparison to the corresponding mock controls (Fig. 6). However a strong and significant 15-fold induction was observed at $10 \mathrm{dpt}$, suggesting that pPPO16 could be activated by another apple pathogen. Regarding $p K F D V 02, G U S$ expression was not significantly induced by $V i$ inoculation in the first 3 days, but considerably raised at $10 \mathrm{dpt}$ in both mock or $\mathrm{Vi}$-sprayed leaves, approximately 20 -fold relative to the beginning of the experiment ( $p K F D V 02: G U S$-nt). The same phenomenon was also observed at $10 \mathrm{dpt}$ in the youngest leaf of each plant which did not receive any treatment (Online Resource 9), suggesting the presence of a different unknown factor affecting $p K F D V 02$.

\section{Discussion}

Our work identified ten potentially functional apple PPO-encoding genes harboring the three known typical domains tyrosinase (PF00264), DWL (PF12142) and KFDV (PF12143), located on two duplicated chromosomes (5 and 10), all being addressed to the chloroplast and distributed in five phylogenetic sub-groups. This result complete the survey that Tran et al. (2012) performed among 25 land plants, describing $P P O$ gene families varying in size (1 to 13) except in the genus Arabidopsis whose genome does not contain $P P O$ sequences. Clustering of $P P O$ genes at the same chromosomal location has already been observed in other plant species and indicates tandem gene duplications (Tran et al. 2012).

In the same chromosomal regions, we also identified six pseudogenes with similarity to $P P O$ but with discrepancies such as deletions, premature stop codons and/or frameshifts, and two $P P O$-like genes of unknown function with only the KFDV domain. Doubts can be raised over their function as true polyphenol oxidases considering that they lack the common central domain of tyrosinase responsible of the oxidation process. Despite these doubts, KFDV genes were conserved in our study as $P P O$-like genes according to the fact that they have homologs in numerous dicot species.

Plant $P P O$ genes are known to be involved in different physiological processes, from stress response to developmental regulation and environmental adaptation, as confirmed by their differential expression patterns in different situations (Thipyapong and Steffens, 1997; Constabel and Barbehenn, 2008; Tran and Constabel, 2011; Thipyapong et al. 2007). This makes regulatory sequences of $P P O$ genes good candidates for diversified strategies of 
intragenesis. Unfortunately in our experiments, further analyses showed that the expression driven by $p K F D V 02$, originally chosen for an expected constitutive activity was in fact modulated by unspecified factors. This result invalidated $p K F D V O 2$ as a good candidate to drive a constitutive but weak expression for apple intragenesis development. On the other hand the fact that we found differential expression of $P P O$ genes in response to $E a$ is coherent with previous works in other plant species showing induction in response to biotic stresses only for some $P P O$ genes, in both incompatible and compatible interactions (Tran and Constabel, 2011; Rinaldi et al. 2007). In our hands MdPPO16 induction in response to Ea has been recorded in three different genotypes ('MM106', 'Evereste' and 'Gala'; Vergne et al. 2014 and this work). MdPPO16 was also shown to be induced by wounding (Boss et al. 1995) and in fruit flesh browning disorder (Di Guardo et al. 2013), suggesting various functions for this gene.

Transient and stable transgenic assays using reporter genes fused to the immediate upstream region from the start codon of MdPPO16 confirmed that this regulatory sequence was efficient to obtain the desired $E a$-inducible expression pattern. Only one stable transgenic line was recovered with the $P P P O 16-G U S$ construction so we cannot affirm that the observed expression profile in that line is not affected, positively or negatively, by insertion effects. Despite this drawback, $p P P O 16$ promoter in $224 \mathrm{C}$ line show a quick and strong induction in leaves challenged with $E a$, in accordance with results get in transient assays with $G U S$ or FIRE reporter genes. Thus we are confident on other results get with this line. In an intragenesis strategy designed to confer resistance to $E a$, the use of such a promoter should ensure the precise induction of the intragene from the beginning of the infection process. Because a functional bacterial T3SS was required for this promoter induction, it should also avoid inappropriate activation in response to MAMPs (Microbial Associated Patterns, Choi and Klessig, 2016) of $E a$ or of other bacteria with similar conserved motifs potentially present on or inside the plant.

Induction of $p P P O 16$ seems to be linked to the loss of cellular integrity. Three lines of evidence support this hypothesis: (i) $p P P O 16$ induction requires $E a$ with a functional T3SS, which enables the injection of the major effector DspA/E into the plant cell, causing cell death (Boureau et al. 2006), (ii) pPPO16 activation in compatible interaction with $V i$ occurred at 10 dpt in our experiments, which correspond to the beginning of tissue rupture by conidiogenesis (Ortega et al. 1998), and (iii) previous work shows the induction of MdPPO16 after wounding (Boss et al. 1995). A specific induction of pPPO16 linked to cell death is particularly interesting in the objective of controlling fire blight disease. It should ensure the induction of the intragene not only in the case of a real bacterial attack but also as a preventive barrier at wound sites caused by insects or climatic events, both acting as entry points for the bacteria. Despite the strong induction of $\mathrm{pPPO} 16$ in response to $\mathrm{Vi}$ infection, it seems however unwise to consider this promoter in intragenic strategies for apple scab control, as it is only activated during the late phase of infection, i.e. conidiogenesis. Induction of a $P P O$ gene during urediospore formation was already noticed in hybrid poplar / Melampsora laricipopulina interaction (Tran and Constabel, 2011).

We did not observe any response of pPPO16 following exogenous application of $\mathrm{H}_{2} \mathrm{O}_{2}$, known as a precocious ROS produced during the oxidative burst during Ea infection process (Vrancken et al. 2013). The concentration of $\mathrm{H}_{2} \mathrm{O}_{2}$ used in that work is moderate and known to modulate several defense genes in apple without leading to impaired tissue integrity (Dugé de Bernonville et al. 2014). The non-response of pPPO16 following that moderate treatment should indicate that the expression driven by this promoter will remain stable despite moderate increase of $\mathrm{H}_{2} \mathrm{O}_{2}$ concentrations known to occur in various stress conditions (Saxena et al. 2016). 
In the search for apple resistance, several cisgenic strategies have already been developed (Krens et al. 2015), but only one case of intragenic strategy has been tested. This construction combined a $\mathrm{R}$ gene ( $R v i 6$ against $\mathrm{Vi}$ ) with a constitutive strong promoter (from the apple Rubisco gene; Joshi et al. 2011). Overexpression of genes downstream R genes in the defense pathways (i.e. regulators and defense genes) can lead to enhanced resistance but with an important energetic cost that might impede primary plant functions or create developmental disorders. For example, constant overexpression of master-switch genes like NPRI (Pieterse and Van Loon, 2004) can lead to lesion mimic phenotypes (Fitzgerald et al. 2004) and be detrimental to plant development (Gurr and Rushton, 2005). Overexpression of phytoalexins or other antimicrobial compounds at high level can also damage tissue integrity (Großkinsky et al. 2012). Therefore, the use of pathogen-inducible promoters to drive regulators of defense pathways, $P R$ genes or toxic antimicrobial genes is a necessity (Gurr and Rushton, 2005). In order to create efficient fire blight resistance in apple, several candidate genes could be placed under the control of the $P P P O 16$ promoter characterized in our study: important regulators of defense pathways like NPR1 (Malnoy et al. 2007), members of calcium-dependant protein kinases family (Kanchiswamy et al. 2013), genes involved in the jasmonic acid pathway (Dugé de Bernonville et al. 2012) or genes that increased oxidation of phenolic compounds (Flachowsky et al. 2010; Gaucher et al. 2013; Hutabarat et al. 2016). The present work represents the first step towards the development of efficient "all native" solutions for apple fire blight resistance. As far as we know, pPPO16 is the first cloned apple promoter inducible by Ea. Further work will be needed to choose optimal candidate genes combining high efficiency for disease resistance, limited risk of break-down and absence of adverse effects on plant physiology. 


\section{Acknowledgements}

This project was funded by the INTRAPOM Project (INRA BAP division) and postdoctoral grants from Region Pays de la Loire and Angers Agglomération (E. Vergne, L. Righetti and M. Gaucher). The plasmid pGREEN II 0800-LUC was kindly provided by Dr. A. Allan (PFR, New Zealand). The plasmid pKGWFS7-35S was kindly provided by J. Jeauffre (IRHS, France). The authors gratefully acknowledge the IRHS-ImHorPhen team and the experimental unit HORTI of INRA Angers for technical assistance in plant maintenance, B. Billy (SNES-GEVES) for technical assistance in flow cytometry and the technical platform ANAN. Technical contributions from M. Jacq, J.G. Bertault and P. Berthelot are also gratefully acknowledged. The authors wish to thank their collaborator Alexandre Degrave for his careful and critical reading of the manuscript.

\section{Author's contribution}

M.G. and L.R. were the main investigators in this study. They performed most of the experiments, analyzed and interpreted data, drafted the manuscript and revised it. E.V. designed the study, performed part of the experiments, analyzed and interpreted data, drafted the manuscript and revised it. S.A., T.D.B., M.N.B. and E.C. actively contributed to the analysis and interpretation of data and revised the manuscript. All authors read and approved the final version.

\section{Conflict of interest}

The authors declare no conflict of interest. 


\section{References}

Barny MA (1995) Erwinia amylovora hrpN mutants, blocked in harpin synthesis, express a reduced virulence on host plants and elicit variable hypersensitive reactions on tobacco. European J. Plant Pathol. 101, 333-340. doi: 10.1007/BF01874789

Borejsza-Wysocka E, Norelli JL, Aldwinckle HS, Malnoy M (2010) Stable expression and phenotypic impact of attacin $E$ transgene in orchard grown apple trees over a 12 years period. BMC Biotechnol. 10, 41. doi: 10.1186/1472-6750-10-41

Boss PK, Gardner RC, Janssen BJ, Ross GS (1995) An apple polyphenol oxidase cDNA is up-regulated in wounded tissues. Plant Mol. Biol. 27, 429-433. doi: 10.1007/BF00020197

Boureau T, El Maarouf-Bouteau H., Garnier A., Brisset MN, Perino C, Pucheu I et al. (2006) DspA/E, a type III effector essential for Erwinia amylovora pathogenicity and growth in planta, induces cell death in host apple and non-host tobacco plants. Mol. Plant-Microbe Interact. 19, 16-24. doi: 10.1094/MPMI-19-0016

Bradford MM (1976) A rapid and sensitive method for the quantification of microgram quantities of protein utilizing the principle of protein-dye binding. Anal. Biochem. 72, 248254. doi : 10.1016/0003-2697(76)90527-3

Chevreau E, Dupuis F, Taglioni JP, Sourice S, Cournol R, Deswartes C et al. (2011) Effect of ectopic expression of the eutypine detoxifying gene Vr-ERE in transgenic apple plants. Plant Cell Tis. Org. Cult. 106, 161-168. doi: 10.1007/s11240-010-9904-4

Choi HW, Klessig DF (2016) DAMPs, MAMPs, and NAMPs in plant innate immunity. BMC Plant Biol. 16, 232.doi: 10.1186/s12870-016-0921-2

Constabel CP, Barbehenn RV (2008) Defensive roles of polyphenol oxidase in plants. In: Induced plant resistance to herbivory. Ed. A. Schaller, (Springer, New York) 253-269.

Daccord N, Celton JM, Linsmith G, Becker C, Choisne N, Schijlen E et al. (2017) Highquality de novo assembly of the apple genome and methylome dynamics of early fruit development. Nat. Genet 49,1099-1106. doi.org/10.1038/ng.3886

Di Guardo M, Tadiello A, Farneti B, Lorenz G, Masuero D, Vrhovsek U et al. (2013) A multidisciplinary approach providing new insight into fruit flesh browning physiology in apple (Malus x domestica Borkh.). PLoS One 8, e78004. doi: 10.1371/journal.pone.0078004 .

Dugé de Bernonville T (2009) Caractérisations histologique, moléculaire et biochimique des interactions compatible et incompatible entre Erwinia amylovora, agent du feu bactérien, et le pommier (Malus $x$ domestica). PhD Thesis Angers University. https://tel.archivesouvertes.fr/tel-00482385/fr/

Dugé de Bernonville T, Gaucher M, Flors V, Gaillard S, Paulin JP, Dat JF et al. (2012) T3SSdependent differential modulations of the jasmonic acid pathway in susceptible and resistant genotypes of Malus spp. challenged with Erwinia amylovora. Plant Sci. 188-189, 1-9. doi: 0.1016/j.plantsci.2012.02.009 
Dugé de Bernonville T, Marolleau B, Staub J, Gaucher M, Brisset MN (2014) Using molecular tools to decipher the complex world of plant resistance inducers: an apple case study. J. Agric. Food Chem. 62, 11403-11411. doi: 10.1021/jf504221x

Edgar RC (2004) MUSCLE: multiple sequence alignment with high accuracy and high throughput. Nucleic Acid Res. 32, 1792-1797. doi: 10.1093/nar/gkh340

Emanuelsson O, Brunak S, von Heijne G, Nielsen H (2007) Locating proteins in the cell using TargetP, SignalP, and related tools. Nature Protocols 2, 953-971. doi: 10.1038/nprot.2007.131

Faize M, Malnoy M, Dupuis F, Chevalier M, Parisi L, Chevreau E (2003) Chitinases of Trichoderma atroviride induce scab resistance and some metabolic changes in two cultivars of apple. Phytopathol. 93, 1496-1504. doi: 10.1094/PHYTO.2003.93.12.1496 .

Fitzgerald HA, Chern MS, Navarre R, Ronald PC (2004) Overexpression of (At)NPR1 in rice leads to a BTH- and environment-induced lesion-mimic/cell death phenotype. Mol. Plant Microbe Interact. 17, 140-151. doi: 10.1094/MPMI.2004.17.2.140

Flachowsky H, Richter K, Kim WS, Geider K, Hanke MV (2008a) Transgenic expression of a viral EPS-depolymerase is potentially useful to induce fire blight resistance in apple. Ann. Applied Biol. 153, 345-355. doi: 10.1111/j.1744-7348.2008.00264.x

Flachowsky H, Peil A, Rollins J, Hanke MV, Lee DH, Richter K. (2008b) Improved fire blight resistance in transgenic apple lines by constitutive overexpression of the $m b r 4$ gene of Malus x baccata. Acta Hort. 793, 287-291. doi: 10.17660/ActaHortic.2008.793.42

Flachowsky H, Szankowski I, Fischer TC, Richter K, Peil A, Höfer M et al. (2010) Transgenic apple plants overexpressing the $L c$ gene of maize show an altered growth habit and increased resistance to apple scab and fire blight. Planta 231, 623-635. doi: $10.1007 / \mathrm{s} 00425-009-1074-4$

Flachowsky H, Halbwirth H, Treutter D, Richter K, Hanke MV, Szankowski I et al. (2012) Silencing of flavanone-3-hydroxylase in apple (Malus $x$ domestica Borkh) leads to accumulation of flavanones, but not to reduced fire blight susceptibility. Plant Physiol. Biochem. 51, 18-25. doi: 10.1016/j.plaphy.2011.10.004

Fulton TM, Chunzoongse J, Tanksley SD (1995) Microprep protocol for extraction of DNA from tomato and other herbaceous plants. Plant Mol. Biol. Rep. 13, 207-209.

Gaucher M, Dugé de Bernonville T, Guyot S, Dat JF, Brisset MN (2013) Same ammo, different weapons: enzymatic extracts from two apple genotypes with contrasted susceptibilities to fire blight (Erwinia amylovora) differentially convert phloridzin and phloretin in vitro. Plant Physiol. Biochem. 72, 178-189. doi: 10.1016/j.plaphy.2013.03.012

Großkinsky DK, van der Graaf E, Roitsch T (2012) Phytoalexin transgenics in crop protection. Plant Sci. 195, 54-70. doi: 10.1016/j.plantsci.2012.06.008

Gurr SJ, Rushton PJ (2005) Engineering plants with increased disease resistance: what are we going to express? Trends Biotech. 23, 275-282. doi: 10.1016/j.tibtech.2005.04.007 
Halpin C (2005) Gene stacking in transgenic plants - the challenge for 21st century plant biotechnology. Plant Biotechnology Journal 3, 141-155 doi: 10.1111/j.14677652.2004.00113.x

Hellens RP, Allan AC, Friel EN, Bolitho K, Grafton K, Templeton MD et al. (2005) Transient expression vectors for functional genomics, quantification of promoter activity and RNA silencing in plants. Plant Methods 1, 1-13. doi: 10.1186/1746-4811-1-13

Herzog K, Flachowsky H, Deising HB, Hanke MV (2012) Heat-shock-mediated elimination of the nptII marker gene in transgenic apple (Malus $\times$ domestica Borkh.). Gene 498, 41-49. doi: 10.1016/j.gene.2012.01.074

Holme IB, Wendt T, Holm PB (2013) Intragenesis and cisgenesis as alternatives to transgenic crop development. Plant Biotech. J. 11, 395-407. doi: 10.1111/pbi.12055

Hood EE, Gelvin SB, Melchers LS, Hoekema A (1993) New Agrobacterium helper plasmids for gene transfer to plants. Transgenic Res. 2, 208-218. doi: 10.1007/BF01977351

Hutabarat OS, Flachowsky H, Regos I, Miosic S, Kaufmann C, Faramarzi S et al. (2016) Transgenic apple plants overexpressing the chalcone 3-hydroxylase gene of Cosmos sulphureus show increased levels of 3-hydroxyphloridzin and reduced susceptibility to apple scab and fire blight. Planta 243, 1213-1224. doi: 10.1007/s00425-016-2475-9

Joshi SG, Schaart JG, Groenwold R, Jacobsen E, Schouten HJ, Krens FA (2011) Functional analysis and expression profiling of HcrVf1 and HcrVf2 for development of scab resistant cisgenic and intragenic apples. Plant Mol. Biol. 75, 579-591. doi: 10.1007/s11103-011-97491

Kanchiswamy CN, Mohanta TK, Capuzzo A, Occhipinti A, Verrillo F, Maffei ME et al. (2013) Differential expression of CPKs and cytosolic $\mathrm{Ca}^{2+}$ variation in resistant and susceptible apple cultivars (Malus $x$ domestica) in response to the pathogen Erwinia amylovora and mechanical wounding. BMC Genomics 14, 760. doi: 10.1186/1471-2164-14760

Karimi M, Inzé D, Depicker A (2002) GATEWAY vectors for Agrobacterium-mediated plant transformation. Trends Plant Sci. 7, 193-195. doi: 10.1016/S1360-1385(02)02251-3

Khan MA, Zhao YF, Korban SS (2012) Molecular mechanisms of pathogenesis and resistance to the bacterial pathogen Erwinia amylovora, causal agent of fire blight disease in Rosaceae. Plant Mol. Biol. Rep. 30, 247-260. doi: 10.1007/s11105-011-0334-1

King EO, Ward MK, Raney DE (1954) Two simple media for the demonstration of pyocyanin and fluorescein. J. Lab. Clin. Med. 44, 301-307.

Kortstee AJ, Khan SA, Helderman C, Trindade LM, Wu Y, Visser RGF et al. (2011) Anthocyanin production as a potential visual selection marker during plant transformation. Transgenic Res. 20, 1253-1264. doi:10.1007/s11248-011-9490-1 
Kost TD, Gessler C, Jänsch M, Flachowsky H, Patocchi A, Broggini GAL (2015) Development of the first cisgenic apple with increased resistance to fire blight. PLoS One 10, e0143980. doi: 10.1371/journal.pone.0143980

Krens FA, Schaart JG, van der Burgh AM, Tinnenbroek-Capel IE, Groenwold R, Kodde LP et al. (2015) Cisgenic apple trees; development, characterization, and performance. Frontiers Plant Sc. 6, 286. doi: 10.3389/fpls.2015.00286

Kumar S, Stecher G, Tamura K (2016) MEGA7: Molecular Evolutionary Genetics Analysis version 7.0 for bigger datasets. Mol. Biol. Evolution 33, 1870-1874. doi : 10.1093/molbev/msw054

Lespinasse Y, Durel CE, Parisi L, Laurens F, Chevalier M, Pinet C (2000) A European project: D.A.R.E. Durable apple resistance in Europe. Acta Hort. 538, 197-200. doi: 10.17660/ActaHortic.2000.538.32

Limera C, Sabbadini S, Sweet JB, Mezetti B (2017) New biotechnological tools for the genetic improvement of major woody fruit species. Frontiers in Plant Science 8, 1418 doi: 10.3389/fpls.2017.01418

Malnoy M, Jin Q, Borejsza-Wysocka EE, He SY, Aldwinckle HS (2007) Overexpression of the apple MpNPRl gene confers increased disease resistance in Malus x domestica. Mol. Plant Microbe Interact. 20, 1568-1580. doi: 10.1094/MPMI-20-12-1568

Malnoy M, Borejsza-Wysocka EE, Pascal-Omenaca L, Aldwinckle HS, Oh CS, Beer SV (2008) Silencing of HIPM, the apple protein that interacts with HrpN of Erwinia amylovora. Acta Hort. 793, 261-264. doi: 10.17660/ActaHortic.2008.793.38

Ortega F, Steiner U, Dehne HW (1998) Induced resistance to apple scab: microscopic studies on the infection cycle of Venturia inaequalis (Cke.) Wint. J. Phytopathol. 146, 399-405. doi: 10.1111/j.1439-0434.1998.tb04771.x

Parisi L, Lespinasse Y, Guillaumes J, Krüger J (1993) A new race of Venturia inaequalis virulent to apples with resistance due to the $V f$ gene. Phytopathol. 83, 533-537. doi: 10.1007/978-94-011-0467-8_16

Parisi L, Lespinasse Y (1996) Pathogenicity of Venturia inaequalis strains of race 6 on apple clones (Malus sp.). Plant Disease 80, 1179-1183. doi: 10.1094/PD-80-1179

Paulin JP (1996) Control of fire blight in European pome fruits. Outlook on Agriculture 25, 49-55.

Paulin JP, Samson R (1973) Le feu bactérien en France. II. Caractères des souches d'Erwinia amylovora (Burrill) isolées du foyer franco-belge. Annales de Phytopathologie 5, 389-397.

Pfaffl MW (2001) A new mathematical model for relative quantification in real-time RTPCR. Nucleic Acid Res. 29, e45.doi: 10.1093/nar/29.9.e45

Pieterse CM, Van Loon LC (2004) NPR1: the spider in the web of induced resistance signaling pathways. Current Opinion Plant Biol. 7, 456-464. doi: 10.1016/j.pbi.2004.05.006 
Pontais I, Treutter D, Paulin JP, Brisset MN (2008) Erwinia amylovora modifies phenolic profiles of susceptible and resistant apple through its type III secretion system. Physiol. Plantarum 132, 262-271. doi: 10.1111/j.1399-3054.2007.01004.x

Pourcel L, Routaboul JM, Cheynier V, Lepiniec L, Debeaujon I (2007) Flavonoid oxidation in plants: from biochemical properties to physiological functions. Trends Plant Sci. 12, 29-36. doi: $10.1016 /$ j.tplants.2006.11.006

R Development Core Team (2016) R: A Language and Environment for Statistical Computing. R Foundation for Statistical Computing, Vienna.

Righetti L, Djennane S, Berthelot P, Cournol R, Wilmot N, Loridon K et al. (2014) Elimination of the nptII marker gene in transgenic apple and pear with a chemically inducible R/Rs recombinase. Plant Cell Tis. Org. Cult. 117, 335-348. doi: 10.1016/j.gene.2012.01.074

Rinaldi C, Kohler A, Frey P, Duchaussoy F, Ningre N, Couloux A et al. (2007) Transcript prowling of poplar leaves upon infection with compatible and incompatible strains of the foliar rust Melampsora laricipopulina. Plant Physiol. 144, 347-366. doi: 10.1104/pp.106.094987

Rommens CM, Haring MA, Swords K, Davies HV, Belknap WR (2007) The intragenic approach as a new extension to traditional plant breeding. Trends Plant Sci. 12, 397-403. doi: 10.1016/j.tplants.2007.08.001

Santos-Rosa M, Poutaraud A, Merdinoglu D, Mestre P (2008) Development of a transient expression system in grapevine via agro-infiltration. Plant Cell Rep. 27, 1053. doi: $10.1007 / \mathrm{s} 00299-008-0531-\mathrm{z}$

Saxena I, Srikanth S, Chen Z (2016) Talk between $\mathrm{H}_{2} \mathrm{O}_{2}$ and interacting signal molecules under plant stress response. Frontiers Plant Sci. 7, 570. doi: 10.3389/fpls.2016.00570

Schouten HJ, Krens FA, Jacobsen E (2006) Do cisgenic plants warrant less stringent oversight? Nature Biotech. 24, 753. doi: 10.1038/nbt0706-753

Sievers F, Wilm A, Dineen D, Gibson TJ, Karplus K, Li W et al. (2011) Fast, scalable generation of high-quality protein multiple sequence alignments using Clustal Omega. Mol. System Biol. 7, 539. doi: 10.1038/msb.2011.75

Skłodowska M, Gajewska E, Kuźniak E, Wielanek M, Mikiciński A, Sobiczewski P (2011) Antioxidant profile and polyphenol oxidase activities in apple leaves after Erwinia amylovora infection and pretreatment with a benzothiadiazole-type resistance inducer (BTH). J. Phytopathol. 159, 495-504. doi: 10.1111/j.1439-0434.2011.01793.x

Small I, Peeters N, Legeai F, Lurin C (2004) Predotar: A tool for rapidly screening proteomes for N-terminal targeting sequences. Proteomics 4, 1581-1590. doi: 10.1002/pmic.200300776

Thipyapong P, Steffens JC (1997) Tomato polyphenol oxidase (differential response of the polyphenol oxidase F promoter to injuries and wound signals). Plant Physiol. 115, 409-418. doi: 10.1104/pp.115.2.409 . 
Thipyapong P, Stout MJ, Attajarusit J (2007) Functional analysis of polyphenol oxidases by antisense/sense technology. Molecules 12,1569-1595. doi: 10.3390/12081569 .

Tran LT, Constabel CP (2011) The polyphenol oxidase gene family in poplar: phylogeny, differential expression and identification of a novel, vacuolar isoform. Planta 234, 799-813. doi: 10.1007/s00425-011-1441-9

Tran LT, Taylor JS, Constabel CP (2012) The polyphenol oxidase gene family in land plants: Lineage-specific duplication and expansion. BMC Genomics 13, 395. doi : 10.1186/14712164-13-395

Vandesompele J, De Preter K, Pattyn F, Poppe B, Van Roy N, De Paepe A et al. (2002) Accurate normalization of real-time quantitative RT-PCR data by geometric averaging of multiple internal control genes. Genome Biol. 3, research0034.1. doi: 10.1186/gb-2002-3-7research0034

Vanneste JL (2000) Fire blight: the disease and its causative agent, Erwinia amylovora. CABI: Wallingford, UK.

Venisse JS, Malnoy M, Faize M, Paulin JP, Brisset MN (2002) Modulation of defense responses of Malus spp. during compatible and incompatible interactions with Erwinia amylovora. Mol. Plant Microbe Interact. 15, 1204-1212. doi : 10.1094/MPMI.2002.15.12.1204

Vergne E, Dugé de Bernonville T, Dupuis F, Sourice S, Cournol R, Berthelot P et al. (2014) Membrane targeted $\mathrm{HrpN}_{\mathrm{Ea}}$ can modulate apple defense gene expression. Mol. Plant Microbe Interact. 27, 125-135. doi: 10.1094/MPMI-10-13-0305-R

Vogt I, Wöhner T, Richter K, Flachowsky H, Sundin GW, Wensing A et al. (2013) Gene-forgene relationship in the host-pathogen system Malus $x$ robusta 5-Erwinia amylovora. New Phytol. 197, 1262-1275. doi: 10.1111/nph.12094

Voinnet O, Rivas S, Mestre P, Baulcombe D (2003) An enhanced transient expression system in plants based on suppression of gene silencing by the p19 protein oftomato bushy stunt virus. Plant J. 33, 949-956. doi: 10.1046/j.1365-313X.2003.01676.x

Vrancken K, Holtappels M, Schoofs H, Deckers T, Valcke R (2013) Pathogenicity and infection strategies of the fire blight pathogen Erwinia amylovora in Rosaceae: State of the art. Microbiol. 159, 823-832. doi: 10.1099/mic.0.064881-0

Yao JL, Tomes S, Gleave AP (2013) Transformation of apple (Malus $\times$ domestica) using mutants of apple acetolactate synthase as a selectable marker and analysis of the T-DNA integration sites. Plant Cell Rep. 32, 703-714. doi: 10.1007/s00299-013-1404-7 


\section{Figure legends}

Fig. 1 Phylogenetic tree of PPO homologs in Rosaceae. The tree was built with the neighborjoining method from the multiple alignment of 30 homologous proteins. Gaps were ignored for tree building and 1000 bootstrap replicates were used to determine the robustness of each node (the bigger the green circle size, the more robust the node). Except for apple for which gene model ID is used, each protein is labeled with two letters (species) and its GenBank ID or XP number. Frv: Fragaria vesca, Prp: Prunus persica (L.) Batsch, Pyb: Pyrus bretschneideri

Fig. 2 Expression profiling MdKFDV01, MdKFDV02 and MdPPO16 in 'MM106' (susceptible to fire blight) and 'Evereste' (resistant to fire blight) genotypes. $\log _{2}$ expression levels were measured in untreated leaves and in mock, $E a$ t3ss or $E a$ wt infiltrated-leaves at 6, 24, 48 hpt. Expression levels for each gene are expressed relatively to the corresponding mean expression level of the untreated MM106 samples and normalized with 3 reference genes (GAPDH, TuA and ACTIN). Bars represent maximum and minimum values from two independent experiments $(\mathrm{n}=2)$

Fig. 3 Expression of GUS gene driven by $p P P O 16$ and $p K F D V 02$ in transient assays. Relative expression of GUS reporter gene driven by $p 35 S, p P P O 16$ and $p K F D V 02$ in untreated (nt, white), mock (light gray) or $E a$ wt (black) -infiltrated leaves (24 hpt) of transiently transformed 'Gala' in vitro plants, six days after agroinfiltration. GUS raw expression levels of each sample were calibrated to the corresponding mean value of the sample $p P P O 16: G U S$ nt, and normalized with $S P E C$ gene to eliminate expression differences due to bacteria. Bars represent SEM from 3 biological repeats $(n=3)$. Letters indicate statistical classes (Kruskal Wallis, $\mathrm{p}<0.05$ )

Fig. 4 pPPO16 and pKFDV02-driven GUS expression in 'Golden Delicious' transgenic lines cultivated in greenhouse and challenged with $E a$. Relative expression of $G U S$ reporter gene driven by $p 35 S, p P P O 16$ and $p K F D V 02$ in untreated leaves, mock or Ea wt-infiltrated leaves (24 hpt) from transgenic lines. GUS raw expression levels of each sample are relative to the corresponding mean value of the sample pPPO16:GUS-nt, and normalized with ACTIN. Numbers 1 and 2 represent independent lines of $p 35 S: G U S$. Bars represent SEM from 3 biological repeats $(\mathrm{n}=3)$. Letters indicate statistical classes (Kruskal Wallis, $p<0.05$ )

Fig. 5 pPPO16 and $p K F D V 02$-driven GUS expression in 'Golden Delicious' transgenic lines challenged with $E a$. Relative expression of $G U S$ reporter driven by $p 35 S, p P P O 16$ and pKFDVO2 in untreated (nt), $\mathrm{H}_{2} \mathrm{O}_{2}$-medium, mock or $\mathrm{H}_{2} \mathrm{O}_{2}$ or $E a \mathrm{t} 3 \mathrm{ss}$ or $E a$ wt-infiltrated leaves $(24 \mathrm{hpt})$ from in vitro plants of transgenic lines. GUS raw expression levels of each sample are relative to the corresponding mean value of the sample pPPO16:GUS-nt, and normalized with ACTIN. Numbers 1 and 2 represent independent lines of $p 35 S: G U S$. Bars represent SEM from six biological repeats $(n=6)$. Letters indicate statistical classes (Kruskal Wallis, $p<0.05$ )

Fig. 6 pPPO16 and pKFDVO2-driven GUS expression in 'Golden Delicious' transgenic lines cultivated in greenhouse and challenged with $V i$. Relative expression levels of GUS reporter gene driven by $p 35 S, p P P O 16$ and $p K F D V 02$ in untreated (nt), mock or $V i$-sprayed leaves (1, $3,10 \mathrm{dpt}$ ) from transgenic lines. GUS raw expression levels of each sample are relative to the corresponding mean value of the sample pPPO16:GUS-nt, and normalized with ACTIN. Numbers 1 and 2 represent independent lines of p35S:GUS. Bars represent SEM from 3 biological repeats $(n=3)$. Letters indicate statistical classes (Kruskal Wallis, $p<0.05$ ) 


\section{Online Resources legends}

Online Resource 1 Pictures of some materials and methods. a) \& b) "In-vitro" growing shoots 4 weeks after rooting. c) Vacuum chamber and pump used to infiltrate bacteria in leaves. d) Growing shoots of young grafts submerged in bacterial suspension to infiltrate bacteria in tissues by vacuum

Online Resource 2 Agrobacterium strains used in this work

Online Resource 3 Primers used in this work

Online Resource 4 Percent identity matrix of CDS and protein sequences of PPO in Malus X domestica

Online Resource 5 Mean Ct values obtained by RT-qPCR with specific primers designed on each coding sequence (CDS) and tested using a 4-fold serial dilution (from 1/16 to 1/4096) of a cDNA pool (all samples of 'Evereste' and 'MM106'). Data were used to calculate primers efficiency and choose the genes for which the expression profiles were analyzed in the different samples (Fig. 2)

Online Resource 6 Gene expression and activity of luciferase driven by pPPO16 and pKFDV02 in transient assays. Relative expression (A) and enzymatic activities (B) of firefly (FIRE) reporter driven by $p 35 S, p P P O 16$ and $p K F D V 02$ in untreated (nt, white), mock (light gray) or $E a$ wt (black) -infiltrated leaves $(24 \mathrm{hpt})$ of transiently transformed 'Golden Delicious' in vitro plants, five days after agroinfiltration. FIRE raw expression levels $(\log 2)$ of each sample were calibrated to the corresponding value of the sample pPPO16:FIRE-nt. Firefly luciferase expression and activity were normalized to Renilla luciferase (REN) expression and activity, respectively $(n=1)$

Online Resource 7 p35S-driven GUS expression in four 'Golden Delicious' transgenic lines cultivated in vitro. Relative expression of GUS reporter gene driven by $p 35 S$ in untreated leaves (nt) from transgenic lines 217F, O, R and S. GUS raw expression level of each sample are relative to the corresponding mean value in untreated leaves of the line $224 \mathrm{C}$ expressing pPPO16:GUS, and normalized with ACTIN. Bars represent SEM from 3 biological repeats $(\mathrm{n}=3)$. Lines $217 \mathrm{O}$ and $\mathrm{S}$ were kept for subsequent analyses

Online Resource 8 Transgenic lines got are free from A. tumefaciens contamination. 2170 \& $\mathrm{S}$ : transgenic lines transformed with p35S:GUS construction, 222D: transgenic line transformed with $p K F D V 02: G U S$ construction, 224C: transgenic lines transformed with pPPO16:GUS construction, T+35S: DNA extraction of A. tumefaciens strain carrying pKGWFS7-p35S:GUS plasmid, as a positive control for transgenic lines transformed with p35S:GUS construction and A. tumefaciens presence, T+pKFDV02: DNA extraction of $E$. Coli strain carrying pKGWFS7-pKFDV02:GUS plasmid as a positive control for transgenic line transformed with $p K F D V 02: G U S$ construction, T+pPPO16: DNA extraction of E. Coli strain carrying pKGWFS7-pPPO16:GUS plasmid as a positive control for transgenic line transformed with $p P P O 16: G U S$ construction, NT: non-transformed 'Gala', T-:H20. EF-1 $\alpha$, NptII, AGRO, p35S:GUS, pKFDV02:GUS, pPPO16:GUS: primer couples

Online Resource 9 Evolution of GUS expression over time in the youngest leaf of transgenic lines cultivated in greenhouse and challenged with $V i$. Relative expression levels of $G U S$ 
reporter gene promoted by $p 35 S, p P P O 16$ and $p K F D V 02$ in untreated leaves from seedlings of transgenic lines carrying the respective promoter in 'Golden Delicious' background. GUS raw expression levels for each sample are relative to the corresponding mean value of the sample pPPO16:GUS-nt (T0), and normalized with ACTIN. Numbers (1) and (2) represent independent lines of $p 35 S$ : GUS. Bars represent SEM from 3 biological repeats $(\mathrm{n}=3)$. Letters

\section{Figure 1}

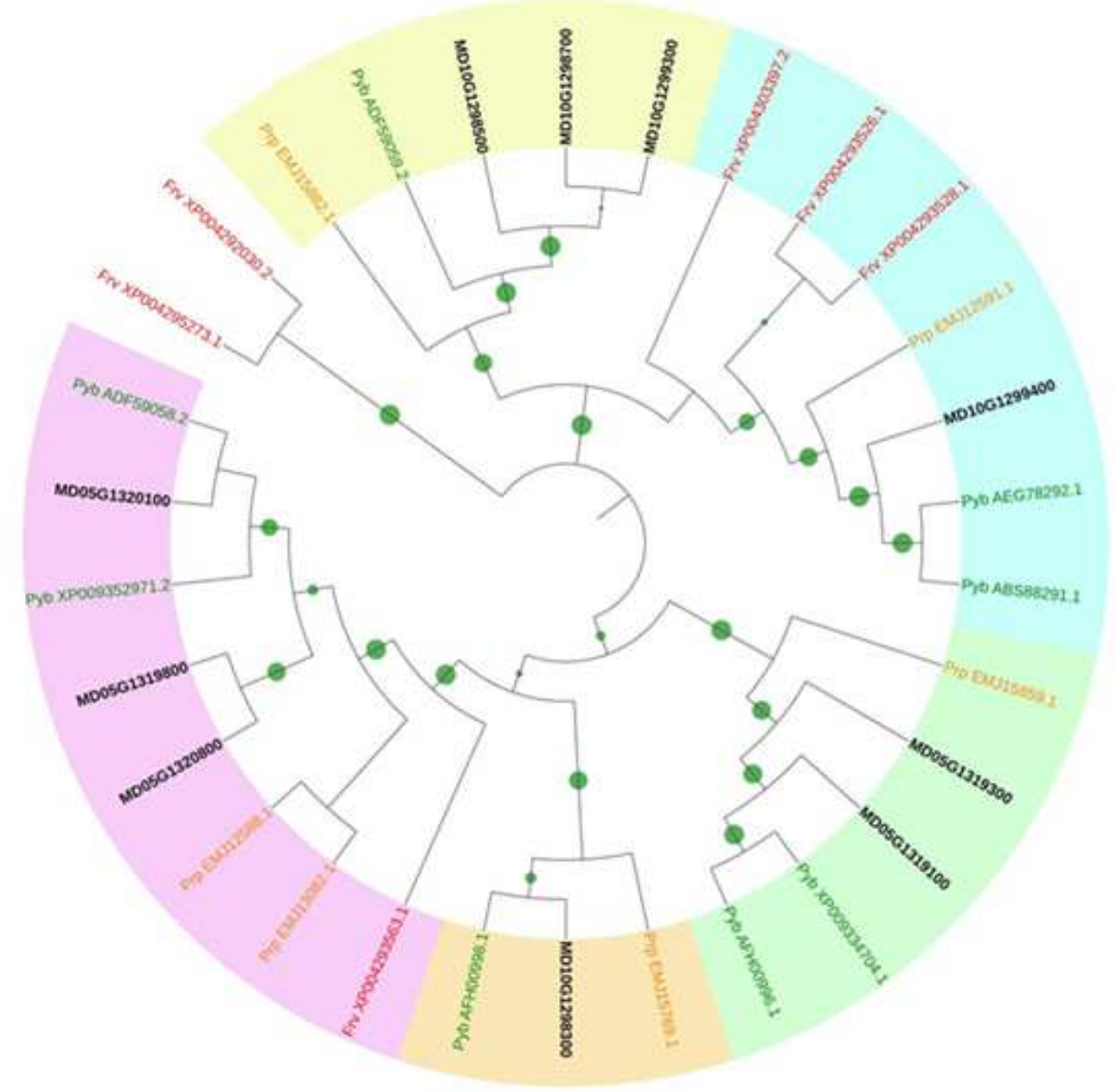




\section{Figure 2}

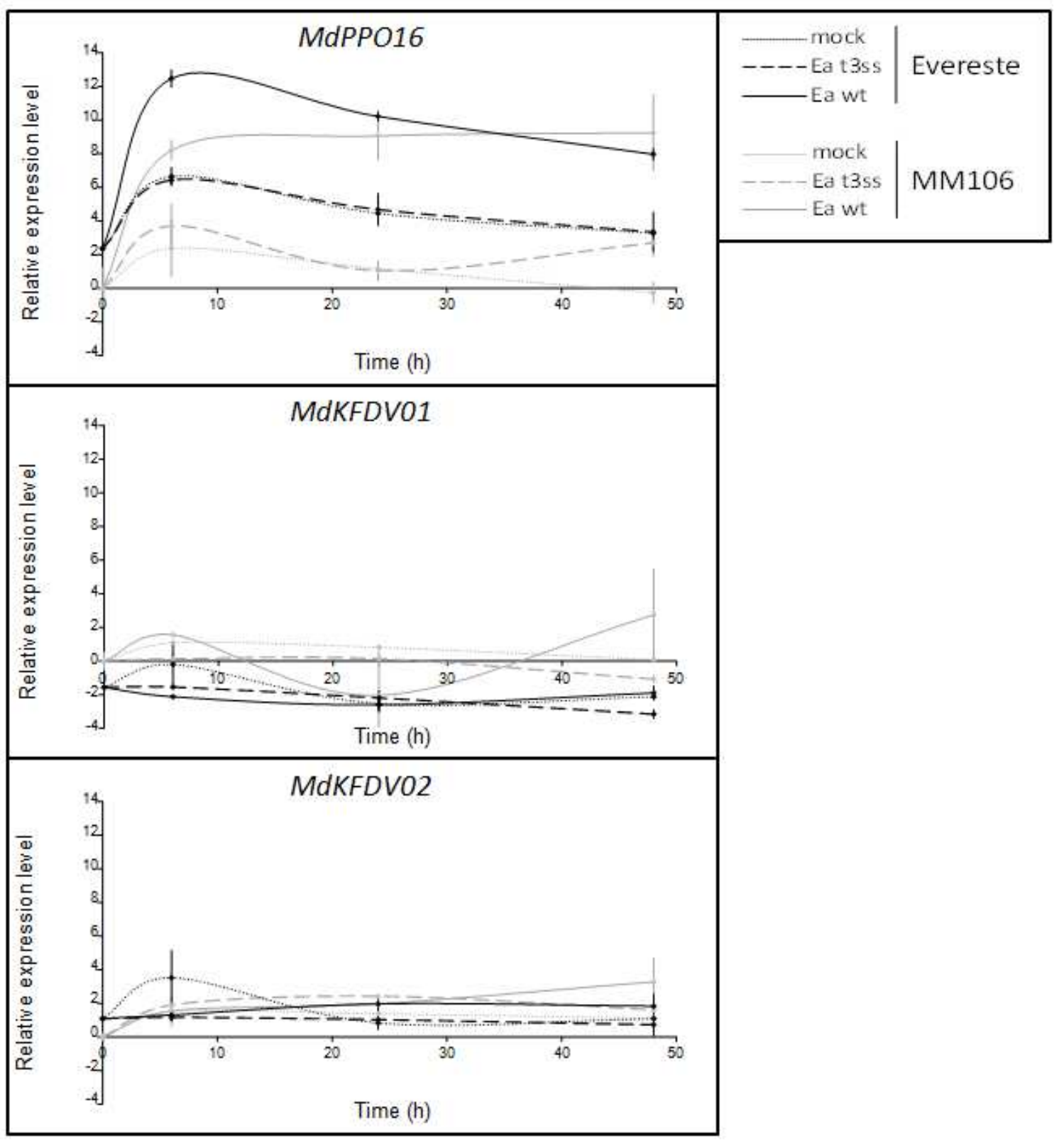


Figure 3

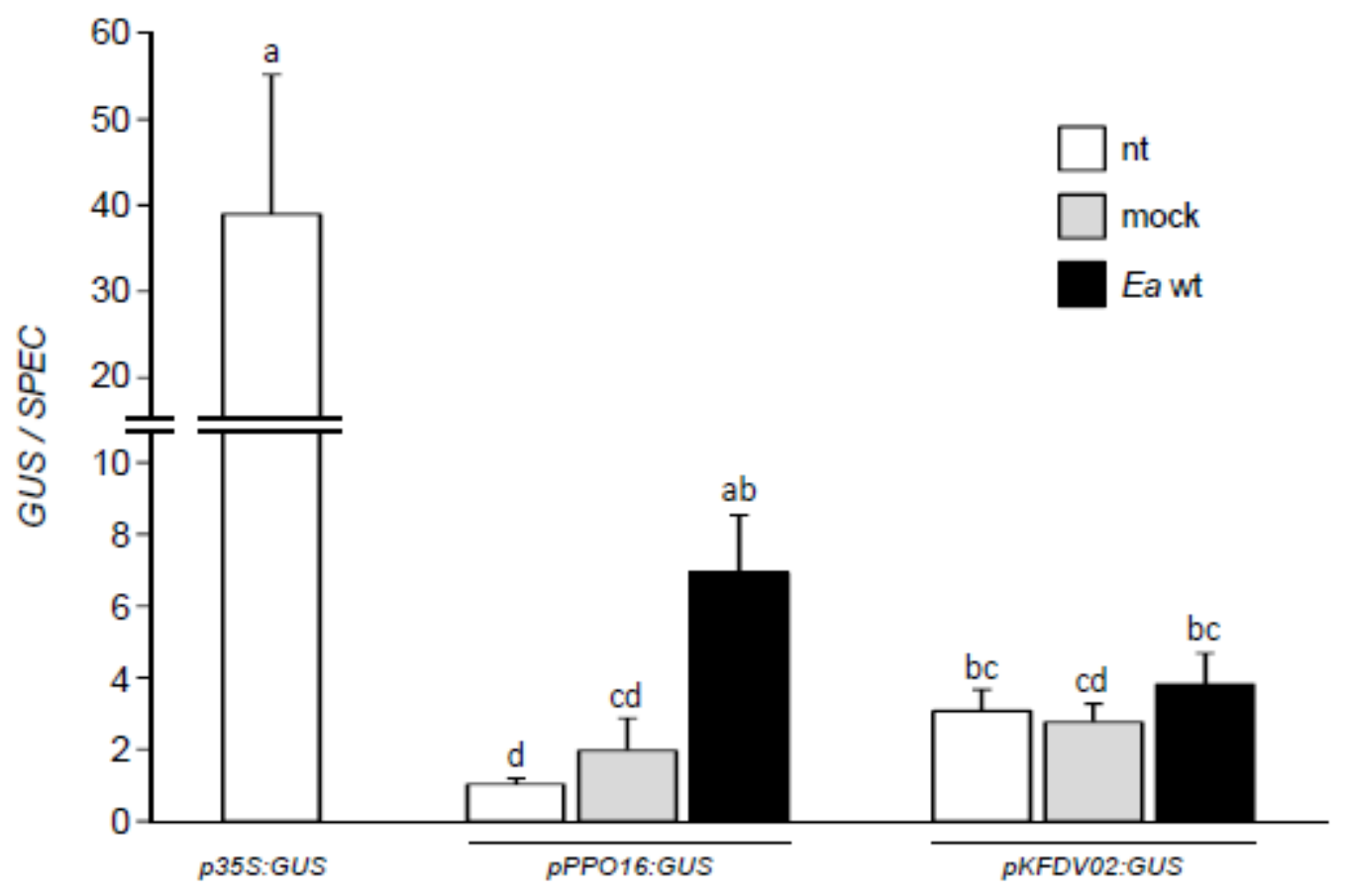




\section{Figure 4}

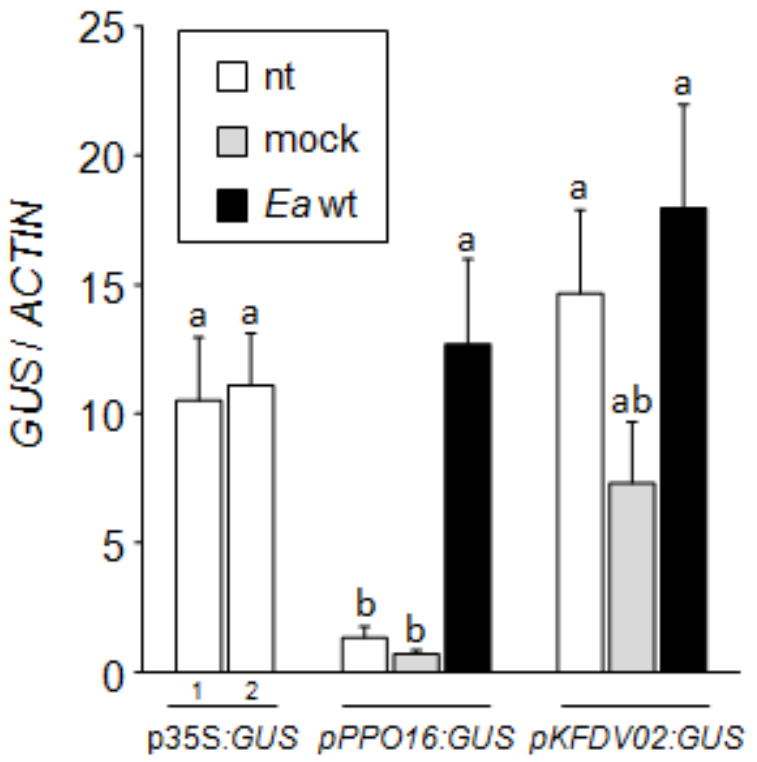


Figure 5

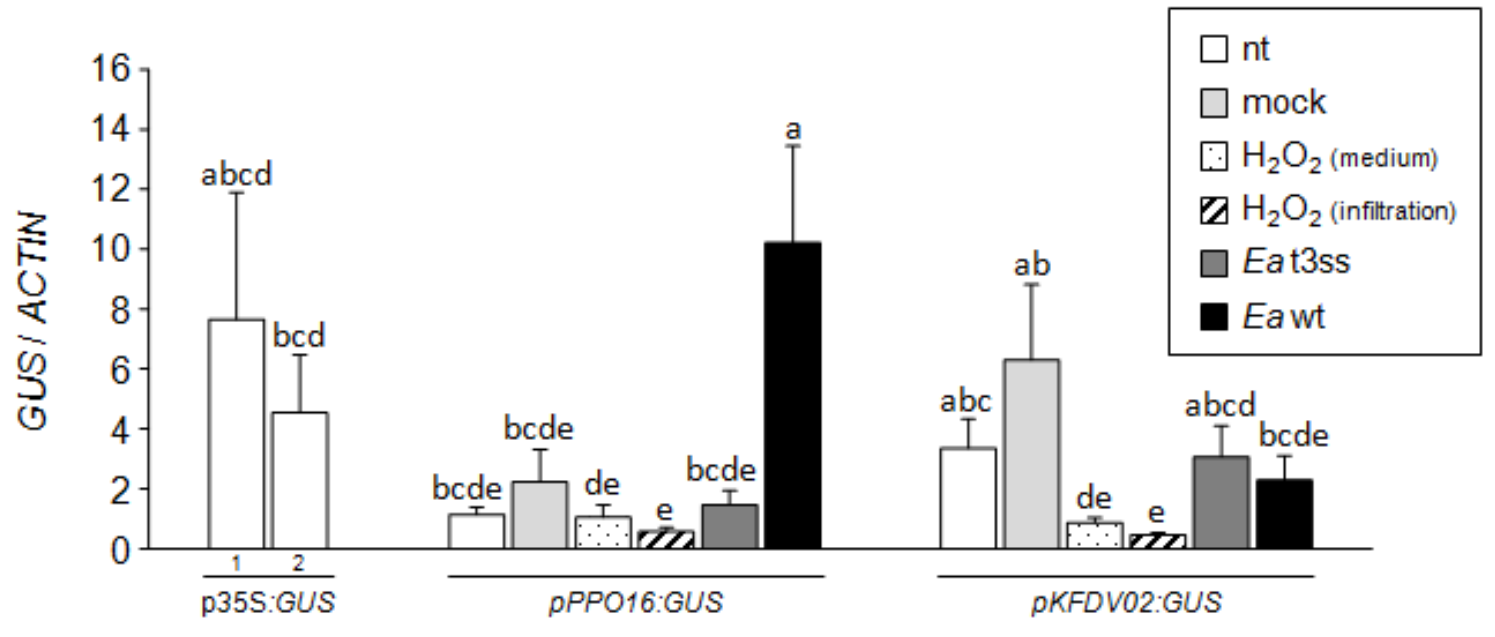




\section{Figure 6}

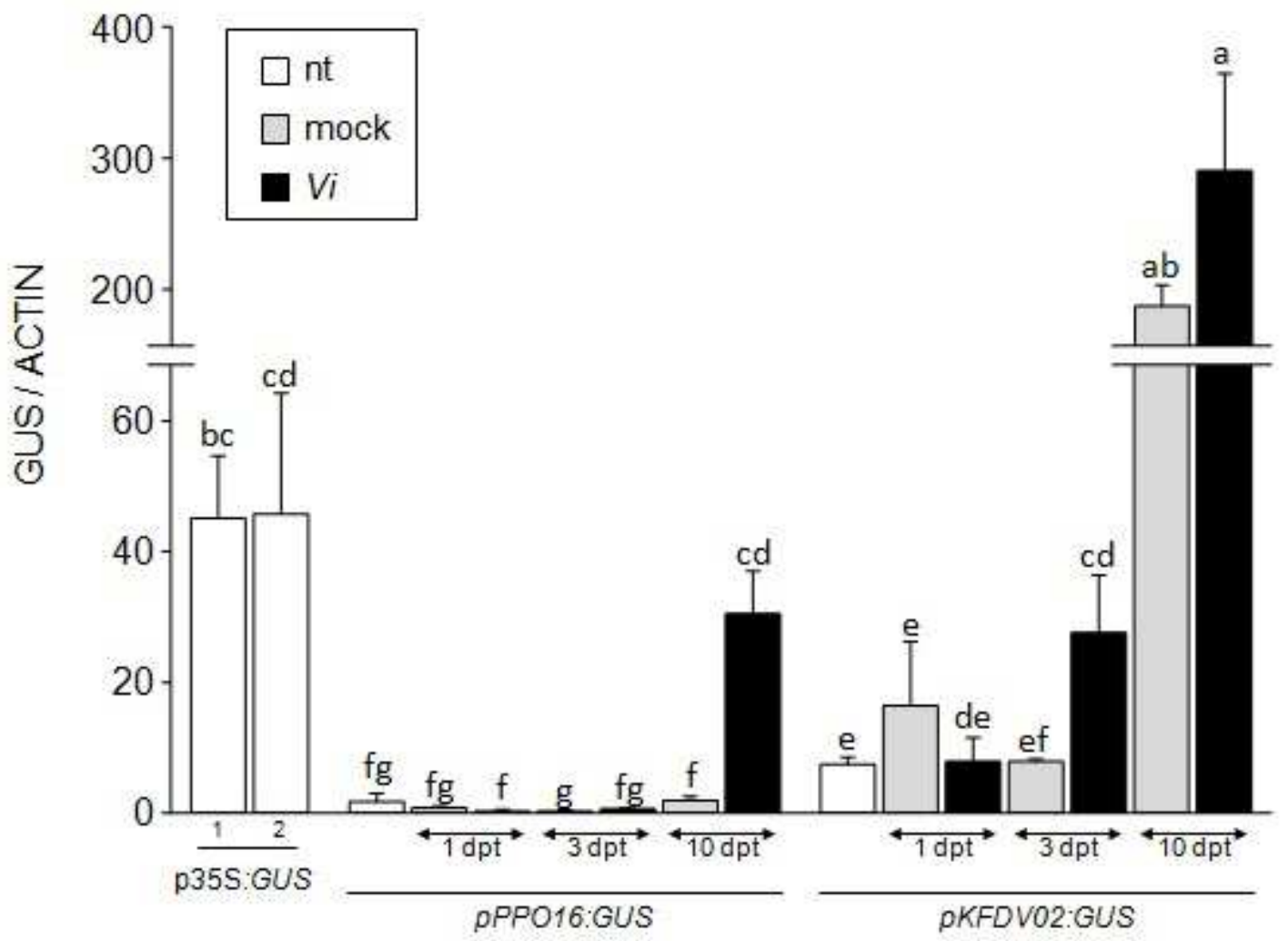


Table 1 Ten $P P O$ genes and two PPO-like genes in Malus x domestica 'Golden Delicious' double haploid 13. Chr: chromosome; nd: not determined; aa: amino acid; TE: transposable element

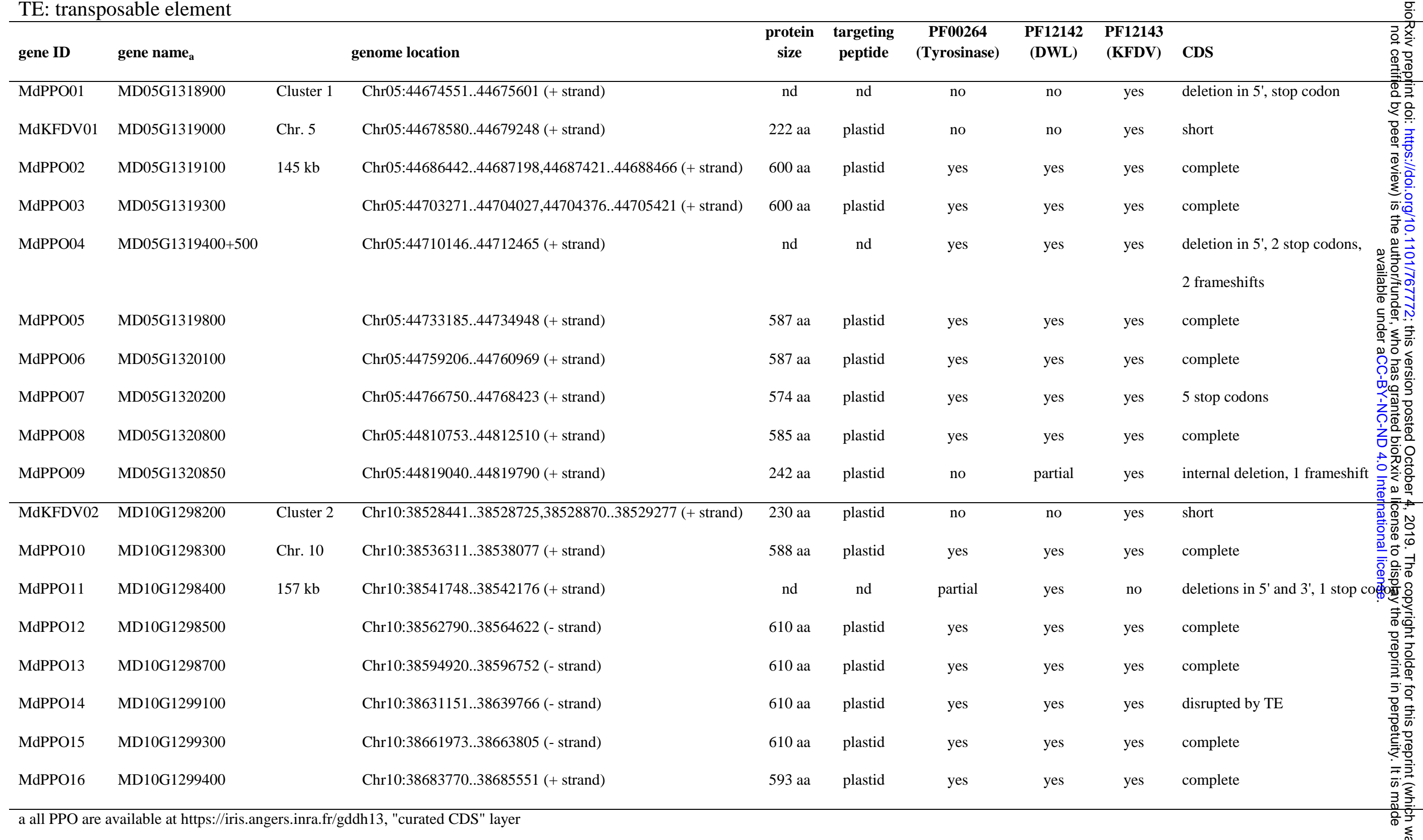

